\title{
The Analysis of Price Competition of Aquatic Products Cold Chain Logistics Enterprises in Fujian
}

\author{
Qiu Jie \\ Fuzhou University of Foreign Studies, Department of \\ Finance, \\ Fuzhou Fujian, China, 350202
}

\author{
Wu Yunhui \\ Fuzhou University of Foreign Studies, Department of \\ Finance, \\ Fuzhou Fujian, China, 350202
}

\begin{abstract}
This article addresses the issue of price competition among aquatic product cold chain logistics companies in Fujian Province. Referenced a large number of aquatic product cold chain logistics in Fujian Province, Information on third-party logistics companies and price competition, etc. Field research on cold chain logistics companies such as Fuzhou Mawei Channel Aquatic Product Trade Center, Warwick New Xiyingli Agricultural Products Wholesale Market, Fuzhou Mingcheng Aquatic Products Logistics Limited company etc. A summary of the status quo and competition of aquatic product cold-chain logistics enterprises across the province, and discusses the causes and advantages and disadvantages of cold-chain logistics enterprises' price competition, and then uses the Bertrand model in game theory to study the complete information static, cartel and the game process of price competition between cold-chain logistics enterprises under complete information dynamics and the final combination of the causes of price competition suggest . Four suggestions for breaking through the price competition dilemma.
\end{abstract}

Keywords-Aquatic products; Cold chain logistics enterprises; Price competition; Game theory; Fujian province

\section{INTRODUCTION}

Aquatic product cold-chain logistics refers to the entire process of processing, distribution and sales of aquatic products after they have been caught or acquired, and all links involved must ensure that aquatic products are always in a lowtemperature environment to ensure aquatic products. Quality and safety, prevention of corruption or contamination of aquatic products in special supply chain systems [1]

In recent years, Fujian Province has taken the development of modern fishery as an important measure to accelerate the development of the marine economy, which has enabled the rapid development of fisheries, which has led to the rapid development of aquatic product cold chain logistics companies. However, most of the cold chain logistics enterprises of aquatic products in Fujian Province are small in scale and have a single function. They mainly provide basic logistics services such as cold chain transportation and cold storage. Lack of funds, facilities and equipment, operation experience and management level, and low level of informationization. Based on the information application of more than 500 agricultural products cold chain enterprises in Fujian Province, professional GPS, transportation management systems, warehouse

Supported by students' outstanding projects at Fuzhou Foreign Language and Tourism Institute (FWXXS17003). management systems, and distribution management are used. The system accounts for only $10 \%$. In addition, cold chain logistics companies have few professional and technical personnel in production management. Most of them are under the management of laypeople. Some technical personnel also lack the expertise in fresh-keeping and cold-storage technology, and their production processes are relatively extensive. The quality of the product has a great impact. In the province, there is not yet one company with strong strength and wide network coverage. It is a leading enterprise that provides professional integrated integrated logistics services for manufacturing enterprises, wholesale and retail enterprises.

High investment cost is one of the key factors hindering the development of cold-chain logistics enterprises. Take refrigerated truck. At present, most refrigerated trucks used by small and medium-sized cold-chain logistics companies are simply configured refrigerated trucks, A standard refrigerated truck is several times more expensive than a regular car. In Fuzhou, Fuzhou Guoyuntong Refrigerated Transport Co.Ltd. which has a turnover of tens of millions, also owns only 73 refrigerated trucks. Therefore, for small and medium-sized cold chain logistics companies with tight funding, Purchasing a regular refrigerated car is not a small expense, Many companies cannot afford.

In terms of transportation, Aquatic product cold chain logistics companies to reduce costs, If it is a long-distance transport to use refrigerated trucks, but the cold is often closed on the way, sometimes refrigerated trucks are insufficient, companies add a layer of quilts to the direct transport of chilled trailers; If it is a short-distance delivery in the city, it is often the responsibility of an ordinary van. Only when there is a large-scale supermarket distribution that has a specific requirement for a cold chain, the company will use a small refrigerated and insulated truck to transport aquatic products. This kind of transportation and distribution method has caused the "broken chain" of cold chain logistics, Seriously affects the quality and safety of aquatic products.

In the construction of the whole cold chain circulation facilities, the cold storage construction accounts for the largest proportion in the enterprise infrastructure investment, while the cold storage construction also focuses on the construction of low temperature warehouses. The cold storage capacity of $79.5 \%$ in Fujian Province is distributed in Fuzhou, Xiamen, Zhangzhou, and Quanzhou, among which self-operated cold- 
chain logistics companies have the largest amount of cold storage construction, and the third-party cold-chain logistics companies have fewer cold storage facilities. The storage capacity utilization rate of cold storage is basically $70 \%-80 \%$. The main storage materials include frozen fish, frozen meat, frozen food and fruits and vegetables.

\section{Problems of AQuAtic Products Cold Chain LOGISTICS ENTERPRISES IN FUJIAN PROVINCE}

\section{A. High product homogeneity}

As mentioned above, the cold chain logistics services provided by Fujian aquatic products cold chain logistics companies are limited to traditional refrigerated transport and warehousing. The products are highly alternative and the service is highly homogenous. The service model is easily imitated by competitors. Differentiation is difficult to achieve. Taking Fuzhou Mingcheng Cold Chain Logistics as an example, $70 \%-80 \%$ of the company's main business revenue is earned by cold storage and refrigerated truck rental [2], and the profit source has a single structure. Under normal circumstances, the greater the possibility of price-price competition between products that are rich in cross-price elasticity, the greater will be the gains or losses suffered by companies through price competition. Therefore, a large part of the fierce price competition among aquatic product logistics companies in Fujian Province is due to the high homogeneity of services.

\section{B. The competition subject is diverse and chaotic.}

At present, the main players in Fujian's cold-chain logistics market are self-operated cold-chain logistics aquatic product processing companies or wholesalers, as well as third-party cold-chain logistics companies, and many individual transport operators lacking cold-chain knowledge. Individual transport operators usually buy a small and medium-sized refrigerated and insulated vehicle, which is specialized in the province's LTL transportation of aquatic products. In the aquatic products and aquatic products market, individual transportation operators waiting for goods everywhere can see that due to limited daily supplies and distribution destinations, many individual transportation operators will spend one morning collecting goods suitable for their own transportation. Therefore, in order to reduce No-load rate, reduce losses, individual transport operators have to reduce prices, exacerbated the level of market competition. With the limited market of cold-chain logistics, the influx of too many competing entities will lead to excessive competition in the cold-chain logistics market in certain areas or regions; on the other hand, it will also bring about the regulation and management of the cold-chain logistics market. Difficulties caused the disorderly competition in the cold chain logistics market [3].

\section{The field of competitive content is narrow.}

There are three main reasons for the cold chain logistics in fujian province. First, the cold chain logistics enterprise of aquatic products is backward due to its hardware and software. Often can only provide basic transportation, Warehousing services, Without the ability to provide integrated cold chain logistics service and whole-process cold chain logistics service, To expand into value-added services, It takes a lot of input, Taking on more risk, For capital, Technology limited selfoperated cold chain logistics enterprises and individual transport operators, It's not going to be easy. Secondly, most of the current aquatic products are sold directly after rough processing. In addition to the necessary refrigerated transportation and storage, There is less demand for high-end cold chain logistics service. Thirdly, due to the lack of understanding of cold chain logistics, Unaware of the dangers of cold chain broken chains, Causes cold chain logistics enterprises to invest in facilities and equipment, Improved technology, Lack of motivation in innovation services, And this is also the whole cold chain logistics development is slow of an important reason.

\section{Market entry barriers are low.}

China's current product standards, technologies, and management standards for cold-chain logistics of aquatic products, including those already announced and currently being developed, add up to only 11 items, and the standard work foundation is at a blank stage [4]. The management of the cold chain logistics market is also managed by the Ministry of Communications, the Ministry of Commerce, and the Ministry of Agriculture, respectively [5]. Multi-headed leadership leads to multiple standards and management is chaotic, and China does not have a dedicated cold chain logistics industry organization or association to assist the government. Management and supervision, but abroad, there are many such organizations. Therefore, in the absence of standard supervision, many companies and individual transport operators without cold chain logistics qualifications have entered the market one after another, resulting in oversupply of the market, diverse and chaotic competition, and fierce price competition that disrupts the normal market competition order. Hamper the development of cold chain logistics.

\section{BREAKTHROUGH IN PRICE COMPETITION}

\section{A. Product differentiation}

From the analysis of the causes of price competition in the third chapter of this article, we can see that high product homogeneity is an important factor leading to price competition. This can also be proved theoretically, Mou Shuzhen used the Tai Tailin model to study the pricing behavior of vendors [8], Zhao Deyu, Gu Haiying, Liu Chen, and explained the impact of product differentiation strategies on the price competition of firms [9] and other scholars, Therefore, one of the effective ways to break through price competition is to create product differentiation. Product differentiation strategy means that companies try to distinguish their products from price war products in order to avoid price wars, highlighting the uniqueness of their products [10]. With 
the change of people's consumption concepts, customers have also put forward higher requirements for cold chain logistics services, and traditional, single cold chain logistics services will gradually fail to meet the needs of customers, Therefore, for the sake of long-term development, companies must add new services and create differentiated service products. In fact, apart from the two basic services of refrigerated transport and warehousing, aquatic product cold chain logistics companies can also consider providing new services such as fullintegrated cold chain service, inventory management, cold chain logistics plan planning, logistics inquiry and cargo tracking. On the one hand, through the addition of new products, the company's own products are differentiated from other companies, reducing the homogeneity of products and avoiding the threat of price competition. On the other hand, these services have high added value and can greatly increase corporate profits. This practice can be verified by Rongqing Logistics, Shanghai Zhengming and other excellent cold-chain logistics companies.

\section{B. Corporate alliances or mergers}

From the point of view of game theory and economics, the combination and merger of companies is one of the effective ways to weaken price competition [11-12]. One of the reasons for the fierce price competition in the cold chain logistics market of aquatic products in Fujian is that the main players in the market are diverse, with mixed results, which disrupts the normal competitive order. Therefore, aquatic product coldchain logistics companies can adopt mergers or acquisitions to integrate a number of small and dispersed third-party thirdparty cold-chain logistics companies, individual transport operators, and self-operated aquatic product cold-chain logistics companies to form several relatively large types. The enterprises, on the one hand, improve the company's strength and competitiveness, reduce the competitive players in the market, and on the other hand, can optimize the allocation of social resources. There are many cases of successful mergers and reorganizations between small companies. For example, glutinous rice is a nationwide road that is composed of eight leading regional logistics companies, including Hubei Avenue, Shandong Pentium, and Guangdong Mengyuan, to solve the limited logistics network. After the freight companies have merged the high-quality resources of each company, the development prospects of glutinous rice are very promising.

In addition, aquaculture enterprises, processing companies, cold-chain logistics companies, distributors and retailers at different levels in different types, industries, and regions can form alliances to discuss issues concerning technological innovation, market segmentation, industry standards, and mutual cooperation. Exchanges and joint formation of a logistics industry that can provide integrated cold chain supply chain services from the source to the retail terminal. The division of labor among companies can also reduce competition. Henan Xinyi Supply Chain Facilitates Standards Development, Such as: National Standardization Management Committee, Ministry of Health Food Safety Standards Committee, China National Institute of Standardization, upstream processing and manufacturing enterprises TEEUWISSEN Telweson Group, Tyson, Unilever, Mengniu,
Yili, eIn the formulation of standards, corporate cooperation and other aspects of discussion and collaboration, and made great progress.tc. and downstream channel companies WalMart, Tesco, KFC, etc. Metro, 7-11 convenience stores, etc.

\section{Cultivating leading enterprises of cold chain logistics of aquatic products}

According to the analysis of the price competition game in the case of the fourth chapter of the Cartel League, we can see that the cartel alliance made up of companies with small differences in strength is not stable, but only one or more companies with strong and self-discipline are present. The alliance is possible. Therefore, the Fujian Provincial Government should cultivate several cold-logistics logistics companies with a comprehensive strength to reduce the negative impact of price competition on the development of the entire industry. It can support some cold chain logistics enterprises with good foundation and great potential, such as the top 100 cold chain logistics enterprises determined by the China National Logistics and Purchasing Federation's Cold Chain Logistics Professional Committee's annual income ranking, including Fujian Hengbing Logistics, Haojia Cold Chain Logistics and Fuzhou State Express refrigerated transport companies were included in the list. These enterprises were given preferential policies in terms of financing, taxation, land acquisition, equipment renewal, etc. to give priority to development, and then to promote the aquatic products cold chain logistics industry in Fujian Province. Cold chain logistics in Shandong Province benefits from the government's strong support to a certain extent in the country's ranking. Its taxation on cold chain logistics companies, land use, approval procedures for the establishment of enterprises, cold chain transportation vehicle management, water use, electricity use, etc. All of them have issued corresponding policy support. In this respect, the Fujian Provincial Government is worth learning from. At the same time, the government can introduce well-known cold chain logistics companies at home and abroad, such as Shanghai Jinjiang, Taikoo Guangzhou, and Zhongchuang, to accelerate the development of the cold chain logistics industry in Fujian Province.

\section{Formulating and improving industry standards}

On the one hand, due to the lack of industry standards and standards, the barriers to market entry are low, and a large number of small-scale aquatic products cold chain logistics companies and individual transport operators without cold chain logistics qualifications are influx, leading to market confusion; On the other hand, there is no basis for cold chain operations, enterprises lack supervision, and the problem of cold chain chain-breaking cannot always be solved. The establishment of cold chain standards is imminent. Although there are few standards and regulations for domestic cold chain logistics, foreign development in this area has been relatively complete. For example, the United Nations Food and Agriculture Organization has so far published 2522 relevant restrictions, and the United States has even more than 4,000 items [13]. Among them, the "Cool Chain Quality Indicator Standard" (see Appendix III) formulated by the American Cold Chain Association specifies the operational regulations that should be observed in highways, aviation, waterways, 
container transport, and long-term, short-term, retail storage. CCQI is widely recognized and applied internationally. The government of Fujian Province should combine the relevant documents issued by the state and the actual situation of the cold chain logistics of aquatic products in this province, refer to foreign standards, and speed up the construction of a cold chain logistics standard system for aquatic products. Through the formulation and improvement of industry standards, the operational norms of cold-chain logistics of aquatic products have been standardized, quality and safety certifications have been carried out, market entry barriers have been raised, and the entire aquatic product cold-chain logistics industry has been standardized [14]. In December last year, Xiamen City released nine series of standards for the "cold-chain logistics of foods" series, the sixth of which is the "Code for the Storage, Transportation, and Marketing of Aquatic Products". The introduction of this standard is to formulate a cold chain for aquatic products in the province. Logistics standards laid a good foundation.

\section{CONCLUSION}

In order to solve the problem of price competition, this paper proposes the following four suggestions: One aquatic product cold chain logistics company must create product differentiation, reduce product homogeneity, increase new high value-added services, and improve corporate profitability; Enterprises in the same industry can be merged to increase the competitiveness of enterprises, and also reduce the main players in the market. Enterprises of different types, industries and regions can form alliances to build supply chains for aquatic products cold chain logistics and promote the development of cold chain logistics industry. Third, Cultivate and introduce cold-chain logistics leading enterprises of aquatic products, which will promote the development of the cold chain logistics industry of aquatic products in Fujian Province. Finally, Formulate and improve industry standards, carry out quality and safety certifications, raise barriers to market entry, and standardize the development of the entire industry.

\section{REFERENCES}

[1] National Development and Reform Commission. Agricultural Cold Chain Logistics Development Plan [Z]. 2010.

[2] Huang Lihua. An analysis of the development of cold chain logistics of aquatic products in Fuzhou - named by Mingcheng Aquatic Products Co., Ltd. [J]. Fujian Transportation Technology, 2015(2):102-106

[3] Feng Tonghai. Research on Competitive Strategy of Third-Party Logistics Enterprises [D]. Shandong: Shandong University, 2008.

[4] Zhong Xiaoyan. Analysis of the Development of Third Party Cold Chain Logistics in Fujian [J]. Journal of Fujian Commercial College, 2013, (5):62-66

[5] Wu Yi. The Development Opportunities and Countermeasures of Fujian Cold Chain Logistics [J]. Journal of Fujian Education Institute, 2012(3):50-54.

[6] Tirole Jean. The Theory of Industrial Organization [J]. Economica, 1988, 1(3):226-227.

[7] Shi Jianxin. Positive Profit Equilibrium in Bertrand's Price Game [J]. Journal of Industrial Engineering and Engineering Management, 2001, 15(2): 82-83.

[8] Yu Shuzhen. A Study of Price Competition and Countermeasures from Game Theory [J]. Journal of Shanxi Finance and Economics University, 2004(4):7-11

[9] Zhao Deyu, Gu Haiying, Liu Chen. Strategies of price competition and product differentiation in duopoly market: a game theory model and its expansion [J]. Journal of Management Science, 2006, 9(5):1-7.

[10] Wu Jianxin. Five Major Coping Strategies for Price Competition [J]. Business Times, 2004(6): 21-22.

[11] Wei Canqiu. Game Theory Model Analysis and Countermeasures of "Price Warfare" Phenomenon [J]. Journal of Sichuan University, 1996, 36(3): 472-475

[12] Zhang Zigang, Xu Hongyi. Optimal allocation of resources derived from price war: acquisition and merger [J]. Journal of Huazhong University of Science and Technology, 2001(9):57-59.

[13] Chen Mingwei. Thinking on the Development of Cold Chain Logistics in Fujian Province [J]. Logistics Technology, 2014(12):82-83.

[14] Chen Bin. Status and Countermeasures of the Development of Aquatic Products Cold Chain Logistics in Fujian Province [J]. Logistics Technology, 2015, 34(5):48-50. 